\title{
Cardiac Cell Lineages that Form the Heart
}

\author{
Sigolène M. Meilhac ${ }^{1}$, Fabienne Lescroart ${ }^{2}$, Cédric Blanpain ${ }^{2,3}$, and Margaret E. Buckingham ${ }^{1}$ \\ ${ }^{1}$ Institut Pasteur, Department of Developmental and Stem Cell Biology, CNRS URA2578, 75015 Paris, France \\ ${ }^{2}$ Université Libre de Bruxelles, IRIBHM, Brussels B-1070, Belgium \\ ${ }^{3}$ WELBIO, Université Libre de Bruxelles, Brussels B-1070, Belgium \\ Correspondence: sigolene.meilhac@pasteur.fr; margaret.buckingham@pasteur.fr
}

\begin{abstract}
Myocardial cells ensure the contractility of the heart, which also depends on other mesodermal cell types for its function. Embryological experiments had identified the sources of cardiac precursor cells. With the advent of genetic engineering, novel tools have been used to reconstruct the lineage tree of cardiac cells that contribute to different parts of the heart, map the development of cardiac regions, and characterize their genetic signature. Such knowledge is of fundamental importance for our understanding of cardiogenesis and also for the diagnosis and treatment of heart malformations.
\end{abstract}

$\mathrm{T}_{\mathrm{p}}^{\mathrm{h}}$ he sources of cells that form the different parts of the heart and their relationships to each other are of major fundamental interest for understanding cardiogenesis. They are also of biomedical significance in the context of congenital heart malformations and for future therapeutic approaches to cardiac malfunction based on stem cell therapies. In this review we mainly focus on myocardial cell lineages, with reference to the origin of the inner endocardial and outer epicardial cell layers of the heart. All these are derived from mesoderm. Neural crest cells, which play an important role in the maturation of the arterial pole of the heart are of neuroectodermal origin and under different genetic regulation, not treated here. We will discuss the current view emerging from a combination of approaches: cell lineage analyses that define the derivatives of a single mesodermal progenitor cell, cell labeling of groups of progenitors that reflects cell movement, and genetic tracing experiments based on the engineered temporal and spatial expression of a reporter gene in different cardiac progenitors and their descendants, with the mouse as the principal model system.

\section{SOURCES OF CARDIAC CELLS IN THE EARLY EMBRYO}

At the epiblast stage of embryonic development (about E6.5 in the mouse), the cardiac fate of individual cells labeled with horseradish peroxidase was determined and different cardiac progenitor cells were shown to be clonally related to paraxial mesoderm and extraembryonic mesoderm, as well as neurectoderm and endoderm (Lawson and Pedersen 1987; Buckingham et al. 1997). These challenging experiments depended on embryo culture and did not permit analysis of cell contributions to the compartments of the maturing heart, mainly because of dilu-

Editors: Margaret Buckingham, Christine L. Mummery, and Kenneth R. Chien

Additional Perspectives on The Biology of Heart Disease available at www.perspectivesinmedicine.org

Copyright (C) 2014 Cold Spring Harbor Laboratory Press; all rights reserved; doi: 10.1101/cshperspect.a013888

Cite this article as Cold Spring Harb Perspect Med 2014;4:a013888 
S.M. Meilhac et al.

tion of the marker. More recent retrospective clonal analysis also indicated these early lineage relationships (Tzouanacou et al. 2009). Grafting of regions of the epiblast showed that progenitors for the endocardium and the pericardium are located in the same region as those for the myocardium (Tam et al. 1997). These experiments also showed that cells are not committed to a cardiac fate at this stage, but will adopt the fate dictated by their location. This continues to be the case during gastrulation, when cells that will form the mesoderm ingress through the primitive streak. Fate mapping has shown that cardiac progenitors ingress early, at the midstreak stage, to become located in the anterior region of the primitive streak, which comprises newly forming mesoderm, in close proximity to progenitors of cranial (head) mesoderm (Kinder et al. 1999). Distinct progenitors of the endocardium or myocardium have been identified in the primitive streak by retroviral labeling in the chick embryo (Wei and Mikawa 2000), however, the timing of segregation of these cell types in the mouse remains controversial, as reviewed in Harris and Black 2010. Mesp1 (Saga et al. 1999) is expressed in the nascent mesoderm in the primitive streak, including cardiac progenitors, as well as in cells that will contribute to the anterior paraxial mesoderm. Genetic tracing with a Mesp1-Cre and Rosa26 conditional reporter shows that almost all cardiac cells in the heart are labeled, so that Mesp1 marks all cardiac progenitors (Fig. 1A,C) (Saga et al. 1999, 2000; Y Saga, unpubl.).

Once cardiac progenitors have progressed through the streak they delaminate and move anteriorly to take up a position on either side of the midline under the head folds, at about E7.5 in the mouse embryo. It is at this stage that the first differentiated myocardial cells are detected in an epithelial crescent-shaped structure, which will subsequently fuse at the midline to form the early heart tube. Mesp1 may play a role in the delamination process, because it activates epithelio-mesenchymal transition (EMT) in the embryonic stem (ES) cell system, with genes like Snail, Twist1, Zeb1, and Zeb2 as downstream targets, that mediate the repression of E-cadherin expression (Bondue et al. 2008; Linds- ley et al. 2008). Although Mesp1 loss of function did not lead to an absence of cardiomyocyte differentiation during embryonic development, possibly owing to redundancy with Mesp2 (Kitajima et al. 2000), Mesp1 plays a key role as an upstream regulator of myocardial cell fate, as indicated by the major increase in cardiomyocyte differentiation following Mesp 1 overexpression in ES cells (Bondue et al. 2008, 2011; David et al. 2008; Lindsley et al. 2008). In the absence of Mesp1 and Mesp2, no mesodermal cells leave the primitive streak, demonstrating the essential role of Mesp1/2 in the delamination of cardiac mesoderm (Kitajima et al. 2000).

\section{MYOCARDIAL CELL LINEAGES: REGIONALIZATION OF THE MYOCARDIUM}

\section{Two Myocardial Cell Lineages that Segregate Early}

Retrospective clonal analysis in the mouse embryo (see Buckingham and Meilhac 2011) indicated that two major lineages contribute to the myocardium of the heart. The first lineage contributes left ventricular myocardium, whereas the second lineage is the source of outflow tract and most right ventricular myocardium, with both lineages contributing to the atria and other parts of the heart (Meilhac et al. 2004). The size of first or second lineage clones gives an indication of when segregation of the two lineages took place, leading to the conclusion that progenitors with these distinct contributions to the heart segregate early during embryonic development, probably at the onset of gastrulation. This genetic approach, which depends on a random recombination event that results in a functional reporter gene in cardiac progenitors and their progeny, does not involve any preconceived idea about the progenitor cell. In combination with DiI labeling to identify the left/ right derivatives of the posterior heart field, retrospective clonal analysis showed that right and left progenitors diverge before first and second heart lineages (Dominguez et al. 2012). For precise information on the timing of segregation and also on the location of first and second lineage progenitors, it will be necessary to de- 


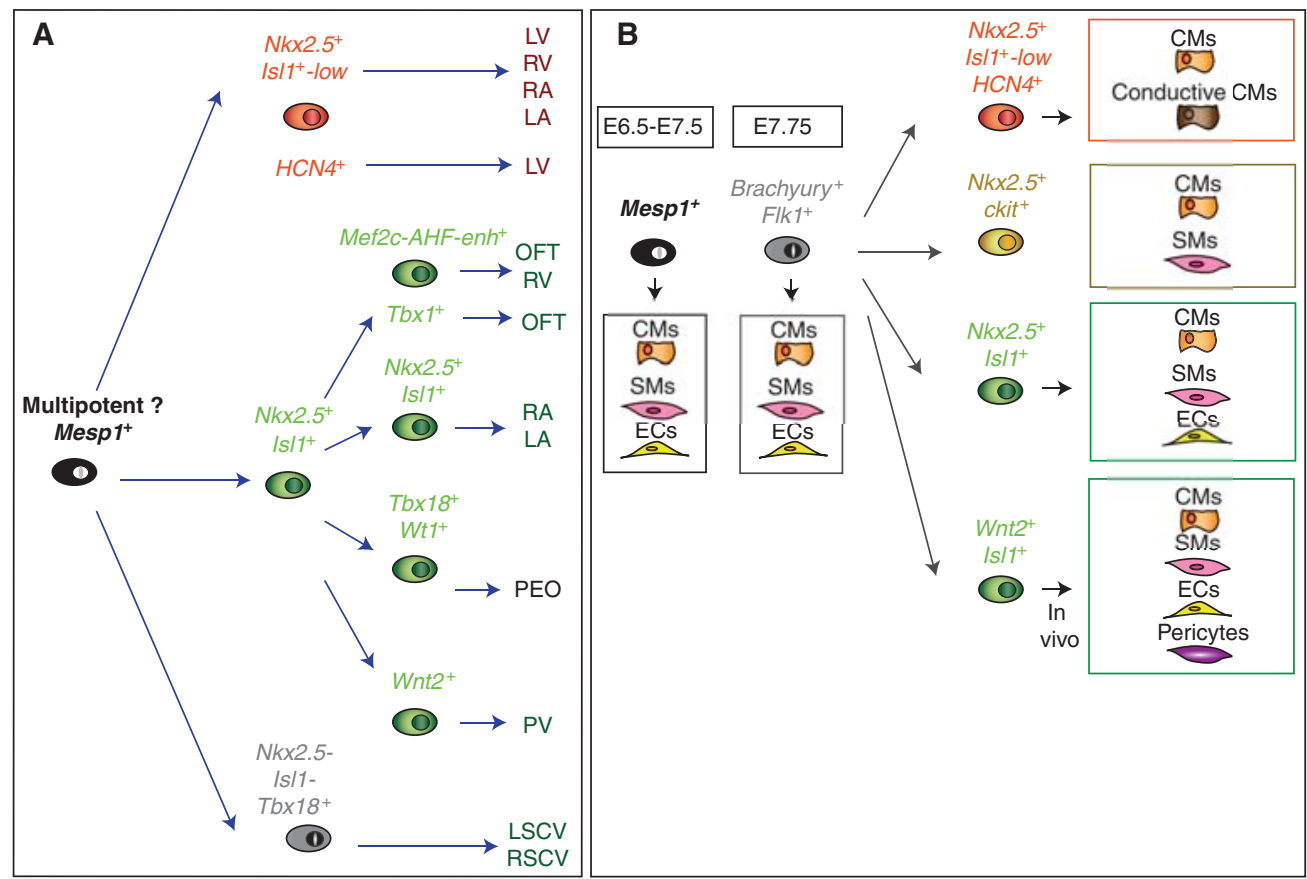

C
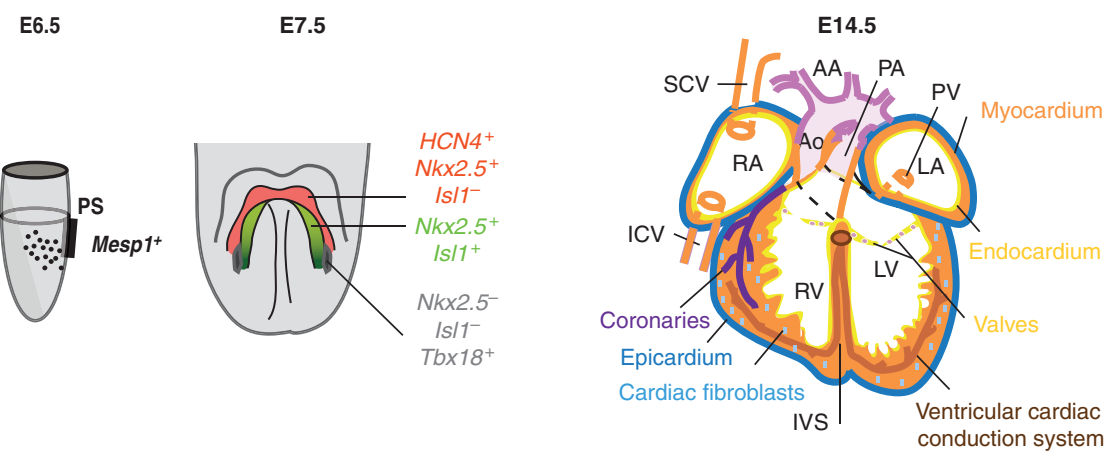

Figure 1. Genetic signature of cardiac precursor cells. (A) Genetic origin of cardiac components, summarizing results from genetic tracing at the population level. $(B)$ In vitro differentiation potential of cardiac precursors, summarizing results from clonal differentiation assays of ES cells or precardiac mesoderm, after cell sorting. $(C)$ Schematic representation of Mesp1-positive cells leaving the primitive streak (PS) (E6.5) contributing to the heart fields (E7.5) and to the tissues of the mature heart (E14.5), with color coding as in $A$ and B. AA, aortic arch arteries; Ao, aorta; CMs, cardiomyocytes; ECs, endothelial or endocardial cells; ICV, inferior caval vein; IVS, interventricular septum; LA, left atrium; LSCV, left superior caval vein; LV, left ventricle; OFT, outflow tract; PA, pulmonary arteries; $\mathrm{PEO}$, proepicardial organ; $\mathrm{PV}$, pulmonary vein; RA; right atrium; RSCV, right superior caval vein; RV, right ventricle; SCV, superior caval vein; SMs, smooth muscle cells.

velop inducible genetic tools for clonal analysis (see Buckingham and Meilhac 2011).

The cardiac crescent and early heart tube mainly contribute to the left ventricular myocardium (Zaffran et al. 2004). Tbx5 and HCN4 are early markers of the cardiac crescent and genetic tracing with an HCN4-Cre shows labeling of the embryonic left ventricle, mainly in the myocardial lineage (Fig. 1A) (Liang et al. 2013; Spater et al. 2013). The concept of two myocardial cell lineages is complemented by the identification of a population of progenitor cells, described as 
S.M. Meilhac et al.

the second heart field (SHF) that does not immediately differentiate into the myocardial cells of the cardiac crescent and newly formed heart tube. These progenitors are located medially to the cardiac crescent (first heart field) (Fig. 2A). Genetic tracing, explant experiments, and fluorescent dye labeling of cells, followed by embryo culture (Kelly et al. 2001; Zaffran et al. 2004; Galli et al. 2008) have shown the contribution of progenitor cells of the anterior and posterior regions of the SHF to the right ventricle (RV) and outflow tract at the arterial pole and to the atria at the venous pole of the heart, respectively. The SHF is marked by Isll expression and genetic tracing with Isl1-Cre showed labeling typical of the second lineage contribution (Cai et al. 2003).
More recently, with new Isl1-Cre lines and more sensitive reporters more extensive labeling of the heart has been observed (Sun et al. 2007; Ma et al. 2008). However, deletion of Isll leads to a phenotype that corresponds to a defect of the second lineage where the morphogenesis of the arterial and venous poles of the heart is affected (Cai et al. 2003).

The early segregation of the two lineages suggests that progenitors of the SHF are distinct from those that form the cardiac crescent and early cardiac tube. In the chick embryo, cells that will contribute to the outflow tract are located more anteriorly in the cardiogenic region of the primitive streak (Garcia-Martinez and Schoenwolf 1993; Abu-Issa and Kirby 2007).

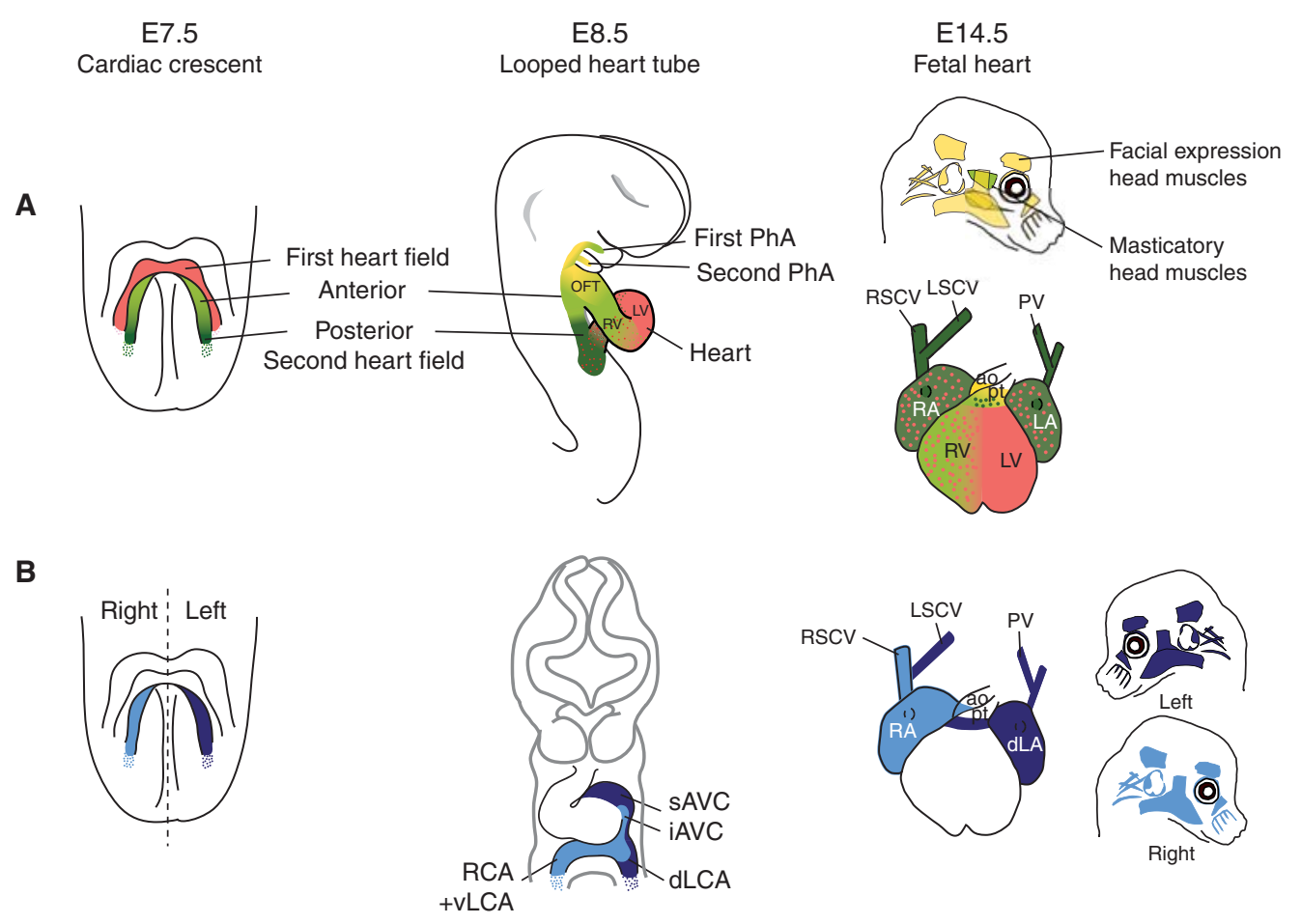

Figure 2. Regionalization of the heart. (A) First (red) and second (green) heart fields and anterior (pale green/ yellow) or posterior (dark green) subdomains of the second heart field are shown at different stages of heart and head development. Regions of the heart with a dual origin are shown with colored dots. (B) Left (dark blue)/ right ( pale blue) derivatives of the second heart field, also showing right and left facial expression muscles in the head. Stages are as in A. ao, aorta; iAVC, inferior atrioventricular canal; sAVC, superior atrioventricular canal; E, embryonic day; LA, left atrium; dLA, dorsal left atrium; dLCA, dorsal left common atrium; vLCA, ventral left common atrium; LSCV, left superior caval vein; LV, left ventricle; OFT, outflow tract; PhA, pharyngeal arches; pt, pulmonary trunk; PV, pulmonary vein; RA, right atrium; RCA, right common atrium; RSCV, right superior caval vein; RV, right ventricle. 
Furthermore, in vivo imaging in the quail embryo, showed that labeled cardiac progenitors move together as coherent groups of cells as they leave the primitive streak, but change their relative anterior/posterior position to a medial/lateral juxtaposition as a result of endoderm folding that produces morphological changes in the overlying mesoderm (Cui et al. 2009). This is consistent with the more subsequent medial location of radioactive grafts from the anterior cardiogenic region of the primitive streak (Rosenquist 1970). Early expression of Mesp1 in cardiac progenitors in the primitive streak provides a genetic marker in the mouse embryo that can potentially distinguish progenitor populations based on genetic tracing. During ES cell differentiation, Mesp1-expressing cells can give rise, at a single cell level, to colonies expressing both Tbx5 and Isl1 suggesting that Mesp1-expressing cells might correspond to common progenitors for both the first and SHFs (Bondue et al. 2011). Prospective clonal analysis using inducible Cre expression in Mesp1-expressing cells will be necessary to investigate whether these cells mark common progenitors for both heart fields in vivo.

\section{Sublineages of the Second Myocardial Cell Lineage that Contribute to the Arterial Pole of the Heart}

The initial identification of the anterior SHF was possible owing to the preferential expression of an Fgf10-LacZ reporter transgene, which marks cells that will form the RV and the outflow tract (Kelly et al. 2001). Other genes such as Fgf8 and $T b x 1$ are also expressed preferentially in the anterior part of the SHF, which is also marked by the activity of a specific Mef $2 \mathrm{C}$ enhancer sequence (Brown et al. 2004; Dodou et al. 2004; Xu et al. 2004). Combined loss of function of Fgf8 / 10 resulted in defects of the RV and outflow tract (OFT) (e.g., Watanabe et al. 2010), consistent with the contribution of these progenitors to the arterial pole of the heart. Loss of function of $T b x 1$ affects myocardium at the base of the pulmonary trunk (Theveniau-Ruissy et al. 2008). DiGeorge syndrome patients, with deletions of a region of chromosome 21 where
TBX1 is located, have tetralogy of Fallot, with overriding aorta, a ventricular septal defect, and right ventricular hyperplasia, thought to be secondary effects of underdevelopment of pulmonary trunk myocardium (Van Praagh 2009).

In addition to the RV and OFT, the arterial pole of the heart is associated with the formation of noncardiac muscles. Genetic tracing experiments have shown that genes such as Mesp1, Nkx2.5, or Isl1 are expressed in progenitor cells that also give rise to a subset of skeletal muscles of the head (Nathan et al. 2008; Harel et al. 2009), which unlike muscles of the trunk and limbs, do not derive from paraxial mesoderm of the somites and are regulated by distinct transcription factors, acting upstream of the myogenic determinants. These progenitors are also marked by the activity of the anterior SHF Mef $2 c$ enhancer sequence (Lescroart et al. 2010). Masticatory and facial expression muscles derive from the first and second pharyngeal (or branchial) arches, respectively (Noden and Francis-West 2006). The branchial arches $(1,2,3,4,6)$ are transient structures that protrude from the pharynx and contain pharyngeal mesoderm that can be regarded as an extension of the SHF, where SHF marker genes such as Fgf10 (Kelly et al. 2001), Isl1 (Cai et al. 2003), and Tbx1 (Xu et al. 2004) are expressed. Myogenic and myocardial progenitor cells are present in the mesodermal core of the first two arches where they begin to segregate, as evidenced by expression of the myogenic determinants MyoD and Myf5 in the more proximal region, whereas SHF markers, such as Isl1, continue to be expressed in cardiac progenitors more distally (Tirosh-Finkel et al. 2006; Nathan et al. 2008). Retrospective clonal analysis (Lescroart et al. 2010) shows that common progenitors give rise to head muscles and to myocardium at the arterial pole of the heart, providing a lineage tree (Fig. 3) in which more anterior head muscles such as the masseter and temporalis, derived from the first pharyngeal arch, are more closely related to the $\mathrm{RV}$, whereas facial expression muscles derived from the second pharyngeal arch are more closely related to OFT myocardium. Left/right lineage segregation is also observed between cardiac and extra- 
S.M. Meilhac et al.

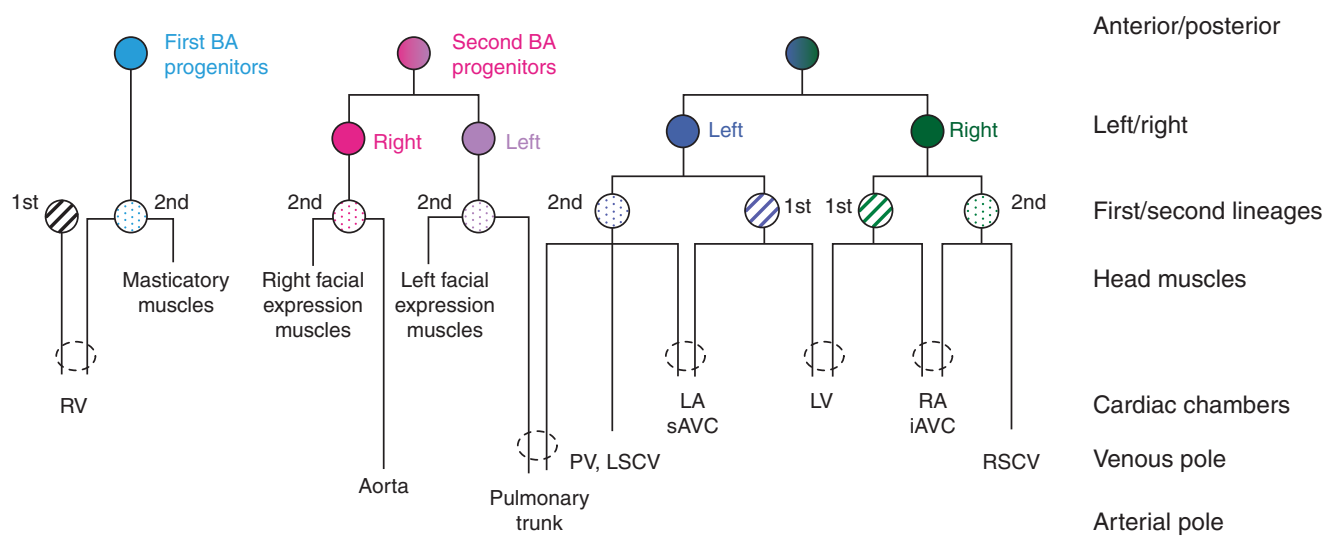

Figure 3. Lineage tree of myocardial cells. A model of the lineage relationships between myocardial cells in different parts of the heart and skeletal muscles of the head is presented, summarizing results obtained in the mouse by retrospective clonal analysis. Progressive steps in lineage segregation are presented following the column on the right of the lineage tree. BA, branchial arch; iAVC, inferior atrioventricular canal; sAVC, superior atrioventricular canal; LA, left atrium; LSCV, left superior caval vein; LV, left ventricle; PV, pulmonary vein; RA, right atrium; RSCV, right superior caval vein; RV, right ventricle.

cardiac derivatives, distinguishing left facial expression muscles and pulmonary trunk myocardium from right facial expression muscles and the myocardium at the base of the aorta (Lescroart et al. 2010). Altogether, these studies indicate that the SHF can be divided into subdomains that contribute to the different regions of the arterial pole of the heart, as well as to facial muscles of the head.

The SHF also gives rise to endothelial cells that form the arterial tree at the outflow region of the heart, as illustrated by genetic tracing experiments using Isll-Cre and anterior SHF Mef2c enhancer-Cre (Verzi et al. 2005; Sun et al. 2007). Mutation of Fgf8/10 (Watanabe et al. 2010) or Tbxl (Zhang et al. 2005) in the SHF leads to abnormal development of arteries derived from this pharyngeal mesoderm.

Smooth muscle cells, which surround the great vessels at the arterial pole, also arise from the SHF as shown by dye labeling in the chick embryo (Waldo et al. 2005; Ward et al. 2005), with the suggestion that SHF progenitors can be bipotent, such that smooth muscle shares a common progenitor with the myocardium (Hutson et al. 2010). The differentiation potential of cardiac progenitors at the clonal level has been essentially assessed using in vitro differ- entiation. During ES cell differentiation, Isl1expressing cardiac progenitors can give rise to myocardial, endothelial, and smooth muscle cells (Moretti et al. 2006), supporting the notion that SHF cells can be multipotent (Fig. 1B). However, although lineage tracing at the population level labeled cardiomyocytes, endothelial cells, and smooth muscle cells (Cai et al. 2003; Sun et al. 2007; Ma et al. 2008), there is no evidence so far that such multipotent SHF progenitors exist in vivo. Furthermore, the intrinsic and extrinsic cues leading to the differentiation of the SHF into a particular fate remain largely unexplored.

From a medical perspective, it is possible that diseases that lead to a defect in the arterial pole of the heart may be accompanied by abnormalities of the skeletal muscles of the head, smooth muscle, and endothelial cells, and arise from a defect in a common progenitor of the cardiomyocytes of the SHF and other derivatives.

\section{Sublineages that Contribute to the Venous Pole of the Heart}

The second myocardial cell lineage also contributes to the atria and this is reflected in the ad- 
dition of cells to the forming heart tube from the posterior part of the SHF, as shown by fluorescent dye labeling (Galli et al. 2008). This posterior region is characterized by Isl1 expression, without expression of anterior SHF markers such as Fgf8/10 or Tbx1. Explant experiments show that these cells have atrial potential, with left/right commitment revealed by transgenic markers (Galli et al. 2008).

As development proceeds, the sinus venosus forms, giving rise to caval vein myocardium. Tbx18 is expressed in this myocardium. The earlier lateral expression of $T b \times 18$ may mark a progenitor pool that gives rise to both caval vein myocardium and the proepicardial organ (PEO), which then segregate following exposure to bone morphogenetic protein (BMP) or fibroblast growth factor (FGF) signaling, respectively, as suggested by experiments in the chick embryo (van Wijk et al. 2009). Surprisingly, the caval vein progenitors in the posterior SHF do not express Isl1 or Nkx2-5, unlike those of the rest of the heart. These distinct properties led to the proposition that the Tbx18-positive progenitors of caval vein myocardium constitute a distinct third heart field (Christoffels et al. 2006; Mommersteeg et al. 2010). Similarly, in the chick a population of cells that is negative for both Isl1 and Nkx2.5 expression and contributes to the development of the sinoatrial node, located in the right superior caval vein, was also suggested to constitute a third heart field (Bressan et al. 2013). Dye labeling of these progenitors in the chick embryo also shows labeled cells in the atria. However, retrospective clonal analysis in the mouse (Lescroart et al. 2012) shows that caval vein myocardium, which includes the sinoatrial node, is not a distinct myocardial cell lineage but rather a sublineage of the SHF. Right caval vein myocardium is closely related to right atrial myocardium, whereas myocardium of the left caval vein forms a sublineage with left atrial myocardium. In both cases the clonal relationship is particularly pronounced for the dorsal region of the atria. Pulmonary vein myocardium also belongs to the left sublineage. Different modes of clonal growth within this myocardium would be consistent with a dual origin for the pulmonary vein from left atrial outgrowth and from addition of cells from the SHF (Lescroart et al. 2012). Interestingly, Wnt2-Cre genetic tracing also marked a posterior subdomain of the SHF that derives from progenitor cells expressing Isll and Gli1. Genetic tracing, using Wnt2-CreERT2 induced at E8.5 and a ROSA26 reporter, labeled cells of the sinus venosus and later myocardial cells of the pulmonary vein as well as smooth muscle and endothelial cells of the pulmonary artery (Peng et al. 2013), suggesting that the contribution of this posterior domain of the SHF might be broader than previously thought and might include a population of multipotent cardiopulmonary progenitors.

Surprisingly, this analysis of lineages at the venous pole also revealed a clonal relationship between the left venous pole and pulmonary trunk myocardium, which forms from the anterior SHF. Because myocardium of the outflow region of the heart is derived exclusively from the second lineage, this is consistent with the second lineage origin of the venous pole. Detailed cell fate mapping, based on fluorescent dye labeling followed by embryo culture, also showed that a subset of cells in the posterior SHF contribute to outflow tract myocardium (Dominguez et al. 2012), suggesting significant cell migration within the SHF (Meilhac et al. 2004; Bajolle et al. 2008). The fate-mapping approach also showed an additional contribution of the posterior SHF to the atrioventricular canal, supported by clonal analysis (Meilhac et al. 2004). The derivatives of left/right regions of the posterior heart field were identified as the superior atrioventricular and the inferior atrioventricular canal, respectively (Fig. 2B) (Dominguez et al. 2012).

The pulmonary trunk myocardium is clonally related to the left venous pole, but this is distinct from the sublineage that contains common progenitors with left facial expression muscles. Pulmonary trunk myocardium therefore derives from two sources: the anterior and the posterior SHF. Given the congenital malformations affecting pulmonary trunk myocardium, it will be important in the future to distinguish between the cellular origins of these defects. Those that are owing to abnormal con- 
S.M. Meilhac et al.

tributions from the posterior SHF sublineage are likely to be associated with venous pole defects. In general, arterial pole malformations are the most frequent form of congenital heart malformation and can frequently be corrected surgically (Gelb et al. 2013). More subtle venous pole defects are not so evident. In a certain number of cases, in which arterial pole surgery did not result in the improvement of heart function, venous pole abnormalities were subsequently identified (Bajolle et al. 2009). It is thus important to check for these rarer defects at the time of arterial pole surgery because some venous pole defects can also be corrected surgically.

\section{MYOCARDIAL LINEAGES IN THE MATURING HEART}

\section{The Interventricular Septum}

As the heart matures, an interventricular septum forms. This outgrowth of myocardium is marked by transgenes expressed in left or right ventricular myocardium, with a spatial distribution of labeled cells that suggests a more extensive left ventricular contribution to the dorsal part of the septum. The extension of clones into the septum from left or right ventricular myocardium also points to a dual origin (Franco et al. 2006). This might suggest that both first and second lineages contribute to the ventricular septum. It is possible that not all precursor cells of the first lineage differentiate at the crescent stage, but that some first lineage cells are still present in the SHF. It is also possible that some right ventricular cells relocate to the left ventricular compartment. A wider contribution of cells initially restricted to a specific subdomain is also seen in genetic tracing with a Tbx1-Cre, which initially labels cells only in the outflow region but subsequently marks cells in a central domain of the RV, which extends into the interventricular septum (Brown et al. 2004).

\section{Compact and Trabeculated Myocardium}

In the heart tube, the walls of the chambers thicken in a process referred to as trabeculation. This is regulated by signals from the endocardi- um and epicardium, via Notch and Neuregulin (Grego-Bessa et al. 2007) or retinoic acid and FGF (Merki et al. 2005; Peshkovsky et al. 2011) signaling cascades, respectively. By E12.5 in the mouse heart, the outer cardiomyocytes that will constitute the compact layer begin to express distinct marker genes, including Tbx20, Hey2, or $M y c n$, not expressed by the inner layer of cardiomyocytes that will form the trabeculae, characterized by expression of genes such as Nppa, Cx40, cdkn1c, or Bmp10 (Moens et al. 1993; Delorme et al. 1997; Kochilas et al. 1999; Nakagawa et al. 1999; Neuhaus et al. 1999; Christoffels et al. 2000; Stennard et al. 2003). These different types of cardiomyocytes are clonally related, as suggested by retrospective clonal analysis. Clones grow with a wedge shape from the compact to the trabeculated layer (Meilhac et al. 2003), which corresponds to decreased proliferation in the trabeculae (Mikawa et al. 1992; Sedmera et al. 2003), compared with the compact layer, which proliferates in response to mitogenic signals from the epicardium (Sucov et al. 2009). Although in zebrafish (Gupta and Poss 2012), one trabeculum arises from the differentiation of multiple cardiac progenitors, it is still not clear whether the polyclonality of the trabeculum is conserved across vertebrates. Recent results on zebrafish have thrown new light on the formation of trabeculae by cardiomyocyte delamination (Staudt et al. 2014).

\section{The Cardiac Conduction System}

The cardiac conduction system generates and transmits electrical impulses that coordinate and regulate contractions of the heart. The origin of the conduction system has been controversial. Based on the expression of some neural crest markers it had been initially proposed that in mammals it derived from neural crest cells (Gorza et al. 1988). However, at least $80 \%$ of the ventricular conduction system derives from cardiac mesoderm, as shown by genetic tracing with a Mesp1-Cre (Kitajima et al. 2006). The absence of labeling of $\sim 20 \%$ of these cells can potentially be explained by an incomplete recombination of the reporter line (Miquerol et al. 2013; L Miquerol, unpubl.), or they may 
derive from a different source. In the chick embryo, ventricular conduction system cells were thought to arise from a distinct population of cells located at the top of the interventricular septum (Lamers et al. 1991; Chan-Thomas et al. 1993) or by recruitment of neighboring cardiomyocytes (Gourdie et al. 1998). Retrospective clonal analysis in the mouse embryo supports the first hypothesis, showing that the central conduction system, including the atrioventricular node and His bundle, segregate early from the precursors of the working myocardium (Miquerol et al. 2013). Expression of Tbx3, which marks the central conduction system, is first seen at the early heart tube stage (Hoogaars et al. 2004), although it is still not proven that these Tbx3-positive cardiomyocytes are conductive progenitors. Recently, in the chick, precursors of the pacemaker cells of the sinoatrial node have been mapped in the mesoderm caudal to the Nkx2-5, Isl1-expressing SHF. Canonical Wnt signaling promotes the specification of these pacemaker cells, whereas it inhibits differentiation into contractile cardiomyocytes (Bressan et al. 2013). However, in the mouse, the sinoatrial node was shown to derive mainly from Isl1- and Tbx18-expressing progenitors (Liang, 2013), suggesting an SHF origin (see sections on sublineages).

In contrast to the central conduction system, the peripheral conduction system shares common ventricular progenitors for contractile and conductive cardiomyocytes until E16.5 (Miquerol et al. 2010). After segregation, cells of both lineages continue to proliferate, although to a lesser extent for the conductive cardiomyocytes. The peripheral conduction system has a dual origin that reflects the distinct origins of the ventricles, such that the RV and right Purkinje fiber network are clonally distinct from the left bundle branch of the conduction system and the left ventricle (Miquerol et al. 2013). By genetic tracing, these two populations can be distinguished based on the expression of Isl1 or HCN4 and Nkx2-5, respectively, in the precursors (Liang et al. 2013).

At present, the possible nonmyocardial sources of the mammalian conduction system are still poorly understood. This information is potentially important for diagnosis and prognosis of certain types of cardiac arrhythmias, which are a frequent human health problem. The successful generation of biological pacemakers for therapeutic purposes from ES or induced pluripotent stem (iPS) cells, for example, would also benefit from knowledge of the origins of different parts of the conduction system.

\section{ENDOCARDIUM}

The endocardium is the inner surface of the heart and is composed of endothelial cells. Genetic tracing that leads to the labeling of the myocardium (Nkx2-5-Cre, Isl1-Cre, as well as with the anterior SHF Mef2C-enhancer-Cre) also results in the labeling of the endocardium (Stanley et al. 2002; Cai et al. 2003; Verzi et al. 2005; Sun et al. 2007; Ma et al. 2008), indicating that these two lineages share spatial and molecular characteristics. In the absence of clonal analysis, it is not clear whether cardiac progenitors are truly bipotent (Linask et al. 1997), but the role of Etv2 might indicate that this is the case. Nkx2-5 is required for the activation of Etv2 (Ferdous et al. 2009), which encodes a transcription factor that is essential for the specification of endocardial cells (De Val et al. 2008). In the absence of Etv2, the cells that should have expressed it differentiate into other muscle lineages including myocardium (Rasmussen et al. 2011). In vitro differentiation of early (Brachyury-GFP ${ }^{+}$-GFP $/ \mathrm{Flk1}^{+}$) cells and late $\left(\mathrm{Isl1}^{+} / \mathrm{Nkx} 2-5^{+} / \mathrm{Flk}^{+}\right)$cardiac progenitors, isolated from mouse embryos or during ES cell differentiation, can give rise to cells expressing endocardial/endothelial markers as well as myocardial markers, suggesting that at both stages these cells correspond to progenitors for both the endocardium and myocardium (Fig. 1B) (Kattman et al. 2006; Moretti et al. 2006). Indeed, using Nfatcl expression as a marker that distinguishes endocardium from other endothelial cells, it was proposed that during ES cell differentiation, multipotent Flk1positive cardiac progenitors can differentiate into both myocardial and endocardial cells in vitro (Misfeldt et al. 2009). It is not clear when 
S.M. Meilhac et al.

the myocardial and the endocardial lineages segregate during cardiovascular development. However, by the time myocardial cells begin to express the first contractile protein genes as the cardiac crescent begins to form, small clusters of more ventrally located endocardial cells can be distinguished (Kaufman and Navaratnam 1981). Cell lineage analyses at the clonal level, with temporal control and a reporter expressed in both cell types, would be essential to establish the existence of a common progenitor for endocardium and myocardium and to determine the time of segregation of these two lineages.

\section{EPICARDIUM}

The epicardium derives from the PEO, a transient group of cells adjacent to the venous pole of the heart, between E8.5 and E10.5 (Schulte et al. 2007). It probably forms from the splanchnic mesoderm of the septum transversum that later gives rise to the diaphragm (Viragh and Challice 1981). The PEO and its derivatives are marked by Isl1-Cre genetic tracing (Moretti et al. 2006; Sun et al. 2007; Zhou et al. 2008b), suggesting a close relationship with other cardiac progenitors. $N k \times 2-5-C r e$ tracing also labels these cells, and in contrast to Isl1, Nkx2-5 is required for PEO formation (Zhou et al. 2008b). The PEO and the epicardium are marked by the expression of Tbx18 and Wt1 (Fig. 1A). Tbx18 is first expressed in anterior lateral mesoderm on either side of the area where Isl1-positive myocardial progenitors are present (Kraus et al. 2001; Mommersteeg et al. 2010). Expression of Cited2, which marks the septum transversum (Dunwoodie et al. 1998), suggests that cells forming this structure may arise initially from a more anterior domain. At the time of foregut closure, morphogenetic changes result in the movement of this anterior territory to a more posterior position at the venous pole of the heart, where the PEO is in close proximity to progenitors of inflow tract myocardium (van Wijk et al. 2009), some of which also express Tbx18 (Christoffels et al. 2006). Later, cells of the PEO cover the surface of the heart to form the epicardium. Subsequently, cells delaminate from the epicardium, undergoing $\mathrm{Wt} 1 /$
Snail-dependent EMT (Martinez-Estrada et al 2010) and enter the myocardium where they constitute the interstitial fibroblast population of the heart and also contribute to the coronary vasculature. A recent study challenged the notion that the endothelial cells of the coronary vasculature derive from the PEO, as these vessels were labeled with a VE-cadherin-CreER line induced at E7.5, which did not label the PEO, indicating that endothelial cells of the coronary veins come from the venous plexus at the sinus venosus (Red-Horse et al. 2010). In contrast, the endothelium of coronary arteries derives from the endocardium, as shown by genetic tracing with an inducible Nfatc1-CreErt2 (Wu et al. 2012). The myocardial potential of the epicardium has been controversial. PEO-derived cells, when manipulated with growth factors in culture, can give rise to myocardial cells (Kruithof et al. 2006; van Wijk et al. 2009). Although classic fate-mapping studies in chick and mouse did not show that the PEO contributes to myocardium in vivo (Winter and Gittenberger-de Groot 2007), more recent genetic tracing experiments with a Wt1-Cre (Zhou et al. 2008a) or Tbx18-Cre (Cai et al. 2008) result in the labeling of some myocardial cells. However, the interpretation of these experiments has been questioned (Christoffels et al. 2009), as Tbx18 can be expressed by some cardiomyocytes and Wt1 is expressed earlier in the primitive streak, complicating the lineage interpretation of these genetic tracing studies. Nevertheless, in these experiments cultured labeled epicardium can result in labeled cardiomyocytes, again indicating the myocardial differentiation potential of epicardial cells. Furthermore, myocardial cells can be generated from cells isolated from the coronary vasculature (Galvez et al. 2008) and after manipulation of cardiac fibroblasts (Qian et al. 2012). The myocardial regenerative potential of the epicardium and its derivatives is a focus of therapeutic interest for cardiomyocyte regeneration in heart failure.

\section{CONCLUSION}

Knowledge about the origins and interrelationships of cells that form the heart is of fundamen- 
tal importance for our understanding of cardiogenesis. It is also very important for the diagnosis and treatment of heart malformations. This is illustrated by the observation that myocardial cells in the pulmonary trunk derive from the same progenitor cells as myocardial cells of the left venous pole, so that malformations of the arterial pole may be associated with more subtle malformations of the venous pole. Detection of such malformations means that it may also be possible to correct them surgically at birth to save the life of the child. The fact that the pulmonary trunk myocardium comes from two distinct sources also has clinical implications for heart disease. The development of therapeutic approaches for the failing heart depends on insights from cardiogenesis. This is particularly true for stem cell-based therapies. The relationships between other cell types of the heart, such as fibroblasts or epicardial cells, and the myocardium underlie attempts to capitalize on the myocardial potential of these cells for cardiac regeneration. Lineage relationships between different compartments of the heart are also of significance in deriving myocardial cells of the appropriate type from iPS or ES cells, before introducing them into the failing heart. Studies of cell lineage and of the function of genes that mark different cardiac progenitor cell populations have opened new perspectives for diagnosis and treatment. Further understanding of myocardial cell behavior, such as proliferation potential, as well as of the mechanisms that define different cardiac progenitors, will continue to impact cardiology.

\section{ACKNOWLEDGMENTS}

Work in the Buckingham laboratory is supported by the Institut Pasteur, the Centre National de la Recherche Scientifique (URA 2578). S.M.M., an Institut National de la Santé Et de la Recherche Médicale research scientist, also thanks France's National Research Agency and the Fondation pour la Recherche Médicale for support. F.L benefits from an EMBO long-term fellowship. C.B. is supported by the Fonds National de la Recherche Scientifique, the Universite Libre de Bruxelles, the European Research Council, the Fondation contre le Cancer, and the Fondation Bettencourt Schueller (C.B. and F.L.).

\section{REFERENCES}

Abu-Issa R, Kirby ML. 2007. Heart field: From mesoderm to heart tube. Annu Rev Cell Dev Biol 23: 45-68.

Bajolle F, Zaffran S, Meilhac SM, Dandonneau M, Chang T, Kelly RG, Buckingham ME. 2008. Myocardium at the base of the aorta and pulmonary trunk is prefigured in the outflow tract of the heart and in subdomains of the second heart field. Dev Biol 313: 25-34.

Bajolle F, Zaffran S, Losay J, Ou P, Buckingham M, Bonnet D. 2009. Conotruncal defects associated with anomalous pulmonary venous connections. Arch Cardiovasc Dis 102: $105-110$.

Bondue A, Lapouge G, Paulissen C, Semeraro C, Iacovino M, Kyba M, Blanpain C. 2008. Mesp1 acts as a master regulator of multipotent cardiovascular progenitor specification. Cell Stem Cell 3: 69-84.

Bondue A, Tannler S, Chiapparo G, Chabab S, Ramialison M, Paulissen C, Beck B, Harvey R, Blanpain C. 2011. Defining the earliest step of cardiovascular progenitor specification during embryonic stem cell differentiation. J Cell Biol 192: 751-765.

Bressan M, Liu G, Mikawa T. 2013. Early mesodermal cues assign avian cardiac pacemaker fate potential in a tertiary heart field. Science 340: 744-748.

Brown CB, Wenning JM, Lu MM, Epstein DJ, Meyers EN, Epstein JA. 2004. Cre-mediated excision of Fgf8 in the Tbx1 expression domain reveals a critical role for Fgf8 in cardiovascular development in the mouse. Dev Biol 267: 190-202.

Buckingham ME, Meilhac SM. 2011. Tracing cells for tracking cell lineage and clonal behavior. Dev Cell 21:394-409.

Buckingham M, Biben C, Lawson KA. 1997. Fate mapping of pre-cardiac cells in the developing mouse. In Genetic control of heart development (ed. Olson EN, Harvey RP Schultz RA, Altman JS), pp. 31-33. HSFP, Strasbourg.

Cai CL, Liang X, Shi Y, Chu PH, Pfaff SL, Chen J, Evans S. 2003. Isl1 identifies a cardiac progenitor population that proliferates prior to differentiation and contributes a majority of cells to the heart. Dev Cell 5: 877-889.

Cai CL, Martin JC, Sun Y, Cui L, Wang L, Ouyang K, Yang L, Bu L, Liang X, Zhang X, et al. 2008. A myocardial lineage derives from Tbx18 epicardial cells. Nature 454: 104108.

Chan-Thomas PS, Thompson RP, Robert B, Yacoub MH, Barton PJ. 1993. Expression of homeobox genes Msx-1 (Hox-7) and Msx-2 (Hox-8) during cardiac development in the chick. Dev Dyn 197: 203-216.

Christoffels VM, Habets PE, Franco D, Campione M, de Jong F, Lamers WH, Bao ZZ, Palmer S, Biben C, Harvey RP et al. 2000. Chamber formation and morphogenesis in the developing mammalian heart. Dev Biol 223: 266-278.

Christoffels VM, Mommersteeg MT, Trowe MO, Prall OW, de Gier-de Vries C, Soufan AT, Bussen M, Schuster-Gossler K, Harvey RP, Moorman AF, et al. 2006. Formation of the venous pole of the heart from an Nkx2-5-negative precursor population requires Tbx18. Circ Res 98: 1555-1563. 
S.M. Meilhac et al.

Christoffels VM, Grieskamp T, Norden J, Mommersteeg MT Rudat C, Kispert A. 2009. Tbx18 and the fate of epicardial progenitors. Nature 458: E8-E9; discussion E9-E10.

Cui C, Cheuvront TJ, Lansford RD, Moreno-Rodriguez RA, Schultheiss TM, Rongish BJ. 2009. Dynamic positional fate map of the primary heart-forming region. Dev Biol 332: $212-222$

David R, Brenner C, Stieber J, Schwarz F, Brunner S, Vollmer M, Mentele E, Muller-Hocker J, Kitajima S, Lickert H, et al. 2008. MesP1 drives vertebrate cardiovascular differentiation through Dkk-1-mediated blockade of Wnt-signalling. Nat Cell Biol 10: 338-345.

Delorme B, Dahl E, Jarry-Guichard T, Briand JP, Willecke K, Gros D, Theveniau-Ruissy M. 1997. Expression pattern of connexin gene products at the early developmental stages of the mouse cardiovascular system. Circ Res 81: 423-437.

De Val S, Chi NC, Meadows SM, Minovitsky S, Anderson JP, Harris IS, Ehlers ML, Agarwal P, Visel A, Xu SM, et al. 2008. Combinatorial regulation of endothelial gene expression by ets and forkhead transcription factors. Cell 135: $1053-1064$.

Dodou E, Verzi MP, Anderson JP, Xu SM, Black BL. 2004 Mef2c is a direct transcriptional target of ISL1 and GATA factors in the anterior heart field during mouse embryonic development. Development 131: 3931-3942.

Dominguez JN, Meilhac SM, Bland YS, Buckingham ME, Brown NA. 2012. Asymmetric fate of the posterior part of the second heart field results in unexpected left/right contributions to both poles of the heart. Circ Res 111: $1323-1335$.

Dunwoodie SL, Rodriguez TA, Beddington RS. 1998. Msg1 and Mrg1, founding members of a gene family, show distinct patterns of gene expression during mouse embryogenesis. Mech Dev 72: 27-40

Ferdous A, Caprioli A, Iacovino M, Martin CM, Morris J, Richardson JA, Latif S, Hammer RE, Harvey RP, Olson $\mathrm{EN}$, et al. 2009. Nkx2 -5 transactivates the Ets-related protein 71 gene and specifies an endothelial/endocardial fate in the developing embryo. Proc Natl Acad Sci 106: 814819.

Franco D, Meilhac SM, Christoffels VM, Kispert A, Buckingham M, Kelly RG. 2006. Left and right ventricular contributions to the formation of the interventricular septum in the mouse heart. Dev Biol 294: 366-375.

Galli D, Dominguez JN, Zaffran S, Munk A, Brown NA, Buckingham ME. 2008. Atrial myocardium derives from the posterior region of the second heart field, which acquires left-right identity as Pitx2c is expressed. Development 135: 1157-1167.

Galvez BG, Sampaolesi M, Barbuti A, Crespi A, Covarello D, Brunelli S, Dellavalle A, Crippa S, Balconi G, Cuccovillo I, et al. 2008. Cardiac mesoangioblasts are committed, selfrenewable progenitors, associated with small vessels of juvenile mouse ventricle. Cell Death Differ 15: 1417-1428.

Garcia-Martinez V, Schoenwolf GC. 1993. Primitive-streak origin of the cardiovascular system in avian embryos. Dev Biol 159: 706-719.

Gelb B, Brueckner M, Chung W, Goldmuntz E, Kaltman J, Kaski JP, Kim R, Kline J, Mercer-Rosa L, Porter G, et al. 2013. The Congenital Heart Disease Genetic Network Study: Rationale, design, and early results. Circ Res 112: 698-706.
Gorza L, Schiaffino S, Vitadello M. 1988. Heart conduction system: A neural crest derivative? Brain Res 457: 360-366.

Gourdie RG, Wei Y, Kim D, Klatt SC, Mikawa T. 1998. Endothelin-induced conversion of embryonic heart muscle cells into impulse-conducting Purkinje fibers. Proc Natl Acad Sci 95: 6815-6818.

Grego-Bessa J, Luna-Zurita L, del Monte G, Bolos V, Melgar P, Arandilla A, Garratt AN, Zang H, Mukouyama YS, Chen $\mathrm{H}$, et al. 2007. Notch signaling is essential for ventricular chamber development. Dev Cell 12: 415-429.

Gupta V, Poss KD. 2012. Clonally dominant cardiomyocytes direct heart morphogenesis. Nature 484: 479-484.

Harel I, Nathan E, Tirosh-Finkel L, Zigdon H, GuimaraesCamboa N, Evans SM, Tzahor E. 2009. Distinct origins and genetic programs of head muscle satellite cells. Dev Cell 16: $822-832$.

Harris IS, Black BL. 2010. Development of the endocardium. Pediatr Cardiol 31: 391-399.

Hoogaars WM, Tessari A, Moorman AF, de Boer PA, Hagoort J, Soufan AT, Campione M, Christoffels VM. 2004 The transcriptional repressor Tbx3 delineates the developing central conduction system of the heart. Cardiovasc Res 62: 489-499.

Hutson MR, Zeng XL, Kim AJ, Antoon E, Harward S, Kirby ML. 2010. Arterial pole progenitors interpret opposing FGF/BMP signals to proliferate or differentiate. Development 137: 3001-3011.

Kattman SJ, Huber TL, Keller GM. 2006. Multipotent flk- $1^{+}$ cardiovascular progenitor cells give rise to the cardiomyocyte, endothelial, and vascular smooth muscle lineages. Dev Cell 11: 723-732.

Kaufman MH, Navaratnam V. 1981. Early differentiation of the heart in mouse embryos. J Anat 133: 235-246.

Kelly RG, Brown NA, Buckingham ME. 2001. The arterial pole of the mouse heart forms from Fgf10-expressing cells in pharyngeal mesoderm. Dev Cell 1: 435-440.

Kinder SJ, Tsang TE, Quinlan GA, Hadjantonakis AK, Nagy A, Tam PP. 1999. The orderly allocation of mesodermal cells to the extraembryonic structures and the anteroposterior axis during gastrulation of the mouse embryo. Development 126: 4691-4701.

Kitajima S, Takagi A, Inoue T, Saga Y. 2000. MesP1 and MesP2 are essential for the development of cardiac mesoderm. Development 127: 3215-3226.

Kitajima S, Miyagawa-Tomita S, Inoue T, Kanno J, Saga Y. 2006. Mesp1-nonexpressing cells contribute to the ventricular cardiac conduction system. Dev Dyn 235: 395402.

Kochilas LK, Li J, Jin F, Buck CA, Epstein JA. 1999. p57Kip2 expression is enhanced during mid-cardiac murine development and is restricted to trabecular myocardium. Pediatr Res 45: 635-642.

Kraus F, Haenig B, Kispert A. 2001. Cloning and expression analysis of the mouse T-box gene Tbx18. Mech Dev 100: $83-86$.

Kruithof BP, van Wijk B, Somi S, Kruithof-de Julio M, Perez Pomares JM, Weesie F, Wessels A, Moorman AF, van den Hoff MJ. 2006. BMP and FGF regulate the differentiation of multipotential pericardial mesoderm into the myocardial or epicardial lineage. Dev Biol 295: 507-522. 
Lamers WH, De Jong F, De Groot IJ, Moorman AF. 1991 The development of the avian conduction system, a review. Eur J Morphol 29: 233-253.

Lawson KA, Pedersen RA. 1987. Cell fate, morphogenetic movement and population kinetics of embryonic endoderm at the time of germ layer formation in the mouse. Development 101: 627-652.

Lescroart F, Kelly RG, Le Garrec JF, Nicolas JF, Meilhac SM, Buckingham M. 2010. Clonal analysis reveals common lineage relationships between head muscles and second heart field derivatives in the mouse embryo. Development 137: 3269-3279.

Lescroart F, Mohun T, Meilhac SM, Bennett M, Buckingham M. 2012. Lineage tree for the venous pole of the heart: Conal analysis clarifies controversial genealogy based on genetic tracing. Circ Res 111: 1313-1322.

Liang X, Wang G, Lin L, Lowe J, Zhang Q, Bu L, Chen Y, Chen J, Sun Y, Evans SM. 2013. HCN4 dynamically marks the first heart field and conduction system precursors. Circ Res 113: 399-407.

Linask KK, Knudsen KA, Gui YH. 1997. N-cadherin-catenin interaction: Necessary component of cardiac cell com partmentalization during early vertebrate heart development. Dev Biol 185: 148-164.

Lindsley RC, Gill JG, Murphy TL, Langer EM, Cai M, Mashayekhi M, Wang W, Niwa N, Nerbonne JM, Kyba M, et al. 2008. Mesp1 coordinately regulates cardiovascular fate restriction and epithelial-mesenchymal transition in differentiating ESCs. Cell Stem Cell 3: 55-68.

Ma Q, Zhou B, Pu WT. 2008. Reassessment of Isl1 and Nkx2-5 cardiac fate maps using a Gata4-based reporter of Cre activity. Dev Biol 323: 98-104.

Martinez-Estrada OM, Lettice LA, Essafi A, Guadix JA, Slight J, Velecela V, Hall E, Reichmann J, Devenney PS, Hohenstein P, et al. 2010. Wt1 is required for cardiovascular progenitor cell formation through transcriptional control of Snail and E-cadherin. Nat Genet 42: 89-93.

Meilhac SM, Kelly RG, Rocancourt D, Eloy-Trinquet S, Nicolas JF, Buckingham ME. 2003. A retrospective clonal analysis of the myocardium reveals two phases of clonal growth in the developing mouse heart. Development 130: 3877-3889.

Meilhac SM, Esner M, Kelly RG, Nicolas JF, Buckingham ME. 2004. The clonal origin of myocardial cells in different regions of the embryonic mouse heart. Dev Cell 6: 685-698.

Merki E, Zamora M, Raya A, Kawakami Y, Wang J, Zhang X, Burch J, Kubalak SW, Kaliman P, Belmonte JC, et al. 2005. Epicardial retinoid $\mathrm{X}$ receptor $\alpha$ is required for myocardial growth and coronary artery formation. Proc Natl Acad Sci 102: 18455-18460.

Mikawa T, Cohen-Gould L, Fischman DA. 1992. Clonal analysis of cardiac morphogenesis in the chicken embryo using a replication-defective retrovirus: III. Polyclonal origin of adjacent ventricular myocytes. Dev Dyn 195: 133-141.

Miquerol L, Moreno-Rascon N, Beyer S, Dupays L, Meilhac SM, Buckingham ME, Franco D, Kelly RG. 2010. Biphasic development of the mammalian ventricular conduction system. Circ Res 107: 153-161.

Miquerol L, Bellon A, Moreno N, Beyer S, Meilhac SM, Buckingham M, Franco D, Kelly RG. 2013. Resolving cell lineage contributions to the ventricular conduction system with a Cx40-GFP allele: A dual contribution of the first and second heart fields. Dev Dyn 242: 665-677.

Misfeldt AM, Boyle SC, Tompkins KL, Bautch VL, Labosky PA, Baldwin HS. 2009. Endocardial cells are a distinct endothelial lineage derived from $\mathrm{Flk}^{+}{ }^{+}$multipotent cardiovascular progenitors. Dev Biol 333: 78-89.

Moens CB, Stanton BR, Parada LF, Rossant J. 1993. Defects in heart and lung development in compound heterozygotes for two different targeted mutations at the N-myc locus. Development 119: 485-499.

Mommersteeg MT, Dominguez JN, Wiese C, Norden J, de Gier-de Vries C, Burch JB, Kispert A, Brown NA, Moorman AF, Christoffels VM. 2010. The sinus venosus progenitors separate and diversify from the first and second heart fields early in development. Cardiovasc Res 87: 92 101.

Moretti A, Caron L, Nakano A, Lam JT, Bernshausen A, Chen Y, Qyang Y, Bu L, Sasaki M, Martin-Puig S, et al. 2006. Multipotent embryonic is $11^{+}$progenitor cells lead to cardiac, smooth muscle, and endothelial cell diversification. Cell 127: 1151-1165.

Nakagawa O, Nakagawa M, Richardson JA, Olson EN, Srivastava D. 1999. HRT1, HRT2, and HRT3: A new subclass of bHLH transcription factors marking specific cardiac, somitic, and pharyngeal arch segments. Dev Biol 216: $72-84$.

Nathan E, Monovich A, Tirosh-Finkel L, Harrelson Z, Rousso T, Rinon A, Harel I, Evans SM, Tzahor E. 2008. The contribution of Islet1-expressing splanchnic mesoderm cells to distinct branchiomeric muscles reveals significant heterogeneity in head muscle development. Development 135: 647-657.

Neuhaus H, Rosen V, Thies RS. 1999. Heart specific expression of mouse BMP-10 a novel member of the TGF- $\beta$ superfamily. Mech Dev 80: 181-184.

Noden DM, Francis-West P. 2006. The differentiation and morphogenesis of craniofacial muscles. Dev Dyn 235: 1194-1218.

Peng T, Tian Y, Boogerd CJ, Lu MM, Kadzik RS, Stewart KM, Evans SM, Morrisey EE. 2013. Coordination of heart and lung co-development by a multipotent cardiopulmonary progenitor. Nature 500: 589-592.

Peshkovsky C, Totong R, Yelon D. 2011. Dependence of cardiac trabeculation on neuregulin signaling and blood flow in zebrafish. Dev Dyn 240: 446-456.

Qian L, Huang Y, Spencer CI, Foley A, Vedantham V, Liu L, Conway SJ, Fu JD, Srivastava D. 2012. In vivo reprogramming of murine cardiac fibroblasts into induced cardiomyocytes. Nature 485: 593-598.

Rasmussen TL, Kweon J, Diekmann MA, Belema-Bedada F Song Q, Bowlin K, Shi X, Ferdous A, Li T, Kyba M, et al. 2011. ER71 directs mesodermal fate decisions during embryogenesis. Development 138: 4801-4812.

Red-Horse K, Ueno H, Weissman IL, Krasnow MA. 2010. Coronary arteries form by developmental reprogramming of venous cells. Nature 464: 549-553.

Rosenquist GC. 1970. Location and movements of cardiogenic cells in the chick embryo: The heart-forming portion of the primitive streak. Dev Biol 22: 461-475. 
S.M. Meilhac et al.

Saga Y, Miyagawa-Tomita S, Takagi A, Kitajima S, Miyazaki J, Inoue T. 1999. MesP1 is expressed in the heart precursor cells and required for the formation of a single heart tube. Development 126: 3437-3447.

Saga Y, Kitajima S, Miyagawa-Tomita S. 2000. Mesp1 expression is the earliest sign of cardiovascular development. Trends Cardiovasc Med 10: 345-352.

Schulte I, Schlueter J, Abu-Issa R, Brand T, Manner J. 2007. Morphological and molecular left-right asymmetries in the development of the proepicardium: A comparative analysis on mouse and chick embryos. Dev Dyn 236: 684-695.

Sedmera D, Reckova M, DeAlmeida A, Coppen SR, Kubalak SW, Gourdie RG, Thompson RP. 2003. Spatiotemporal pattern of commitment to slowed proliferation in the embryonic mouse heart indicates progressive differentiation of the cardiac conduction system. Anat Rec A Discov Mol Cell Evol Biol 274: 773-777.

Spater D, Abramczuk MK, Buac K, Zangi L, Stachel MW, Clarke J, Sahara M, Ludwig A, Chien KR. 2013. A HCN4 ${ }^{+}$ cardiomyogenic progenitor derived from the first heart field and human pluripotent stem cells. Nat Cell Biol 15: $1098-1106$.

Stanley EG, Biben C, Elefanty A, Barnett L, Koentgen F, Robb L, Harvey RP. 2002. Efficient Cre-mediated deletion in cardiac progenitor cells conferred by a $3^{\prime} \mathrm{UTR}$-ires-Cre allele of the homeobox gene Nkx2-5. Int J Dev Biol 46: 431-439.

Staudt DW, Liu J, Thorn KS, Stuurman N, Liebling M, Stainier DY. 2014. High-resolution imaging of cardiomyocyte behavior reveals two distinct steps in ventricular trabeculation. Development 141: 585-593.

Stennard FA, Costa MW, Elliott DA, Rankin S, Haast SJ, Lai D, McDonald LP, Niederreither K, Dolle P, Bruneau BG, et al. 2003. Cardiac T-box factor Tbx20 directly interacts with Nkx2-5, GATA4, and GATA5 in regulation of gene expression in the developing heart. Dev Biol 262: $206-$ 224.

Sucov HM, Gu Y, Thomas S, Li P, Pashmforoush M. 2009. Epicardial control of myocardial proliferation and morphogenesis. Pediatr Cardiol 30: 617-625.

Sun Y, Liang X, Najafi N, Cass M, Lin L, Cai CL, Chen J, Evans SM. 2007. Islet 1 is expressed in distinct cardiovascular lineages, including pacemaker and coronary vascular cells. Dev Biol 304: 286-296.

Tam PP, Parameswaran M, Kinder SJ, Weinberger RP. 1997. The allocation of epiblast cells to the embryonic heart and other mesodermal lineages: The role of ingression and tissue movement during gastrulation. Development 124: $1631-1642$.

Theveniau-Ruissy M, Dandonneau M, Mesbah K, Ghez O, Mattei MG, Miquerol L, Kelly RG. 2008. The del22q11.2 candidate gene Tbxl controls regional outflow tract identity and coronary artery patterning. Circ Res 103: 142-148.

Tirosh-Finkel L, Elhanany H, Rinon A, Tzahor E. 2006. Mesoderm progenitor cells of common origin contribute to the head musculature and the cardiac outflow tract. Development 133: 1943-1953.

Tzouanacou E, Wegener A, Wymeersch FJ, Wilson V, Nicolas JF. 2009. Redefining the progression of lineage segregations during mammalian embryogenesis by clonal analysis. Dev Cell 17: 365-376.
Van Praagh R. 2009. The first Stella van Praagh memorial lecture: The history and anatomy of tetralogy of Fallot. Semin Thorac Cardiovasc Surg Pediatr Card Surg Annu 2009: 19-38.

van Wijk B, van den Berg G, Abu-Issa R, Barnett P, van der Velden S, Schmidt M, Ruijter JM, Kirby ML, Moorman AF, van den Hoff MJ. 2009. Epicardium and myocardium separate from a common precursor pool by crosstalk between bone morphogenetic protein- and fibroblast growth factor-signaling pathways. Circ Res 105: 431-441.

Verzi MP, McCulley DJ, De Val S, Dodou E, Black BL. 2005. The right ventricle, outflow tract, and ventricular septum comprise a restricted expression domain within the secondary/anterior heart field. Dev Biol 287: 134-145.

Viragh S, Challice CE. 1981. The origin of the epicardium and the embryonic myocardial circulation in the mouse. Anat $\operatorname{Rec} 201$ : 157-168.

Waldo KL, Hutson MR, Ward CC, Zdanowicz M, Stadt HA, Kumiski D, Abu-Issa R, Kirby ML. 2005. Secondary heart field contributes myocardium and smooth muscle to the arterial pole of the developing heart. Dev Biol 281: 78-90.

Ward C, Stadt H, Hutson M, Kirby ML. 2005. Ablation of the secondary heart field leads to tetralogy of Fallot and pulmonary atresia. Dev Biol 284: 72-83.

Watanabe Y, Miyagawa-Tomita S, Vincent SD, Kelly RG, Moon AM, Buckingham ME. 2010. Role of mesodermal FGF8 and FGF10 overlaps in the development of the arterial pole of the heart and pharyngeal arch arteries. Circ Res 106: 495-503.

Wei Y, Mikawa T. 2000. Fate diversity of primitive streak cells during heart field formation in ovo. Dev Dyn 219: 505513.

Winter EM, Gittenberger-de Groot AC. 2007. Epicardiumderived cells in cardiogenesis and cardiac regeneration. Cell Mol Life Sci 64: 692-703.

Wu B, Zhang Z, Lui W, Chen X, Wang Y, Chamberlain AA, Moreno-Rodriguez RA, Markwald RR, O'Rourke BP, Sharp DJ, et al. 2012. Endocardial cells form the coronary arteries by angiogenesis through myocardial-endocardial VEGF signaling. Cell 151: 1083-1096.

Xu H, Morishima M, Wylie JN, Schwartz RJ, Bruneau BG, Lindsay EA, Baldini A. 2004. Tbx1 has a dual role in the morphogenesis of the cardiac outflow tract. Development 131: 3217-3227.

Zaffran S, Kelly RG, Meilhac SM, Buckingham ME, Brown NA. 2004. Right ventricular myocardium derives from the anterior heart field. Circ Res 95: 261-268.

Zhang Z, Cerrato F, Xu H, Vitelli F, Morishima M, Vincentz J, Furuta Y, Ma L, Martin JF, Baldini A, et al. 2005. Tbxl expression in pharyngeal epithelia is necessary for pharyngeal arch artery development. Development 132: 53075315.

Zhou B, Ma Q, Rajagopal S, Wu SM, Domian I, Rivera-Feliciano J, Jiang D, von Gise A, Ikeda S, Chien KR, et al. 2008a. Epicardial progenitors contribute to the cardiomyocyte lineage in the developing heart. Nature 454: 109-113.

Zhou B, von Gise A, Ma Q, Rivera-Feliciano J, Pu WT. 2008b. Nkx2-5- and Isl1-expressing cardiac progenitors contribute to proepicardium. Biochem Biophys Res Commun 375: 450-453. 


\section{$\&_{\mathrm{CSH}}^{\infty} \&$ Cold Spring Harbor

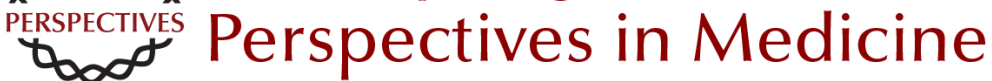

\section{Cardiac Cell Lineages that Form the Heart}

Sigolène M. Meilhac, Fabienne Lescroart, Cédric Blanpain and Margaret E. Buckingham

Cold Spring Harb Perspect Med 2014; doi: 10.1101/cshperspect.a013888

Subject Collection The Biology of Heart Disease

The Genetic Basis of Aortic Aneurysm Mark E. Lindsay and Harry C. Dietz

\section{Personalized Genomes and Cardiovascular \\ Disease \\ Kiran Musunuru}

Complex Genetics and the Etiology of Human

Congenital Heart Disease

Bruce D. Gelb and Wendy K. Chung

Genetic Networks Governing Heart Development Ashley J. Waardenberg, Mirana Ramialison, Romaric Bouveret, et al.

Heart Fields and Cardiac Morphogenesis Robert G. Kelly, Margaret E. Buckingham and Antoon F. Moorman

Regenerative Medicine: Transforming the Drug Discovery and Development Paradigm Sotirios K. Karathanasis

Myocardial Tissue Engineering: In Vitro Models Gordana Vunjak Novakovic, Thomas Eschenhagen and Christine Mummery

Pluripotent Stem Cell Models of Human Heart

Disease

Alessandra Moretti, Karl-Ludwig Laugwitz, Tatjana

Dorn, et al.
Cardiac Cell Lineages that Form the Heart Sigolène M. Meilhac, Fabienne Lescroart, Cédric Blanpain, et al.

Synthetic Chemically Modified mRNA (modRNA):

Toward a New Technology Platform for

Cardiovascular Biology and Medicine Kenneth R. Chien, Lior Zangi and Kathy O. Lui

Next-Generation Models of Human Cardiogenesis via Genome Editing

Xiaojun Lian, Jiejia Xu, Jinsong Li, et al.

How to Make a Heart Valve: From Embryonic Development to Bioengineering of Living Valve Substitutes

Donal MacGrogan, Guillermo Luxán, Anita Driessen-Mol, et al.

Insights into the Genetic Structure of Congenital Heart Disease from Human and Murine Studies on Monogenic Disorders Terence Prendiville, Patrick Y. Jay and William T. $\mathrm{Pu}$

Cardiovascular Drug Discovery: A Perspective from a Research-Based Pharmaceutical Company G. Gromo, J. Mann and J.D. Fitzgerald

Genetics and Disease of Ventricular Muscle Diane Fatkin, Christine E. Seidman and Jonathan G. Seidman

Embryonic Heart Progenitors and Cardiogenesis Thomas Brade, Luna S. Pane, Alessandra Moretti, et al.

For additional articles in this collection, see http://perspectivesinmedicine.cshlp.org/cgi/collection/ 